\title{
Kritisch bestuurskundig onderwijs
}

\author{
Een pleidooi voor productieve subversiviteit ${ }^{*}$
}

\author{
Mark van Ostaijen \& Shivant Jhagroe
}

\begin{abstract}
Welke rol speelt kritiek binnen het bestuurskundig onderwijs? In dit artikel worden de genormaliseerde opvattingen van het huidige beleidsbestuurskundig onderwijs bevraagd. Door de zelfpresentatie van bestuurskundige opleidingen te problematiseren bespreken de auteurs de dominantie van instrumentele kennis. Het artikel benadrukt het belang van kritische kennis en kritische methoden en de rol van 'productieve subversiviteit', om bestuurskundige opleidingen te herbronnen.
\end{abstract}

'The function of education is to teach one to think intensively and to think critically.' In dit artikel gaan we na in hoeverre bestuurskundig onderwijs functioneert volgens deze stelling van Martin Luther King. Want hoe is het gesteld met het kritische potentieel van bestuurskundig onderwijs? Meer specifiek: wat zijn de betekenis, positie en potentie van 'kritiek' in bestuurskundig onderwijs? Daarbij vertrekken we vanuit de assumptie dat kritisch denkvermogen in onderwijs, en dus in een pedagogische setting, geen aardige bijkomstigheid maar didactisch noodzakelijk is. In dit artikel verkennen we de belangrijkste uitdagingen. We bespreken dominante opvattingen van het huidige beleidsbestuurskundig onderwijs en benadrukken het belang van kritisch bestuurskundige kennis en methoden.

\section{Bestuurskundig onderwijs: reflectie op de zelfpresentatie}

Om het kritisch potentieel van bestuurskundig onderwijs te belichten verkennen we eerst hoe verschillende opleidingen zichzelf presenteren. Hierbij maken we gebruik van het werk van de Franse sociologe Nathalie Heinich. Zij stelt (2019, p. 58) dat identiteiten uit meerdere elementen bestaan, namelijk (1) toewijzing door anderen (hoe men je van buitenaf ziet) (2) zelfperceptie door jezelf (hoe je jezelf ziet) en (3) presentatie voor anderen (hoe je jezelf aan anderen presenteert). In deze bijdrage staan we stil bij het laatste element, presentatie naar anderen, dat wil zeggen, hoe bestuurskundeopleidingen zich naar buiten toe presenteren. Dat doen we middels een kritische rondgang langs de websites van Nederlandstalige bestuurskundeopleidingen (najaar 2019).

* Dr. M.A.C. van Ostaijen is universitair docent aan het Departement Bestuurskunde en Sociologie van de Erasmus Universiteit Rotterdam.

Dr. S. S. Jhagroe is universitair docent aan het Instituut Bestuurskunde, Faculty of Governance and Global Affairs, Universiteit Leiden. 
Zo werft men in Leiden met de stelling: 'Als jij graag nadenkt over bestuurlijke oplossingen voor maatschappelijke issues, dan zit je bij Bestuurskunde goed' (LU). In Rotterdam vraagt men zich af: 'Wil jij een bijdrage leveren aan het oplossen van maatschappelijke vraagstukken? Dan is de bachelor in Bestuurskunde (...) echt iets voor jou' (EUR). En in Utrecht stelt men: 'Om antwoorden te kunnen vinden zijn verschillende perspectieven nodig' (UU). Wat opvalt, is dat de bestuurskundige vrijwel overal wordt gepresenteerd als probleemoplosser. Zo stelt men in Tilburg dat je "bij Bestuurskunde wordt opgeleid tot een expert die een ministerie, een bedrijf of een instelling adviezen geeft over maatschappelijke vraagstukken zoals klimaatverandering, criminaliteit en armoede' (TiU). En in Nijmegen positioneert men bestuurskundigen als mensen die 'midden in de maatschappij staan' en zich bezighouden met het 'oplossen van de problemen die daarin spelen'. Met daarbij het vooruitzicht: 'Wil je expert worden van de grootste organisatie binnen Nederland, de overheid?' (RUN). Tot slot kent men in Delft een duidelijk beroepsprofiel: 'In de eerste plaats word je bij ons opgeleid tot ingenieur' (TU Delft). De bestuurskundige, zo valt hieruit op te maken, wordt vrijwel overal gepresenteerd als probleemoplossende bruggenbouwer, expert of ingenieur.

De manier waarop opleidingen zichzelf presenteren, sluit aan op eerdere bevindingen die aantonen dat de bestuurskundige identiteit gebaseerd is op kennisintegratie en toepassingsgerichtheid (Van Ostaijen, 2016). Zodoende beroept ook het bestuurskundige onderwijs zich op een interdisciplinair zelfbeeld met een sterke nadruk op 'toepassing' en 'kennisintegratie' als centrale elementen. Daarbij wordt met kennisintegratie bedoeld dat de bestuurskunde theoretische inzichten ontleent aan andere (mono)disciplines, om een pluraliteit aan inzichten samenhangend te integreren (De Jong, 1988; Van Braam, 1989; Rutgers, 1993). Daarnaast is het toepassingsgerichte karakter erop gericht om steevast 'praktijkrelevant' te zijn, aangezien 'praktische relevantie de rechtvaardiging vormt voor bestuurskunde als zelfstandige activiteit' (Rutgers, 2004, p. 268). En dus werven bestuurskundeopleidingen studenten met het vooruitzicht om uiteindelijk probleemoplossende bruggenbouwers of adviseurs te worden. Zoals bestuurskundig onderzoek vanaf de jaren zeventig van de vorige eeuw vooral 'science for policy' was, lijkt bestuurskundig onderwijs in lijn daarmee vooral education for policy te zijn (Braun, Fenger, 't Hart, Van der Veer, \& Verheij, 2015, p. 83).

Deze zelfpresentatie valt te problematiseren. Het is ten eerste een nogal enge benadering van wetenschappelijke kennis. Het impliceert dat maatschappelijke problemen met wetenschappelijke kennis 'op te lossen' zijn. Daarnaast doet deze zelfpresentatie weinig recht aan het kritisch potentieel van bestuurskundig onderwijs in Nederland.

\section{Beleidsbestuurskunde als heersende kennisopvatting}

Het doet ertoe wat voor soort, ofwel wat voor type kennis wordt verwacht van studenten, zowel tijdens als na hun studie. Zoals Bacon stelde dat kennis in een kennismaatschappij macht is, is een claim op 'kennis' per definitie omstreden. En 
Tabel 1 Burawoy's matrix van disciplinaire kennis

\begin{tabular}{lll}
\hline & Academische publieken & Extra-academische publieken \\
\hline Instrumentele kennis & Professioneel & Beleid \\
Reflexieve kennis & Kritisch & Publiek \\
\hline
\end{tabular}

academisch onderwijs speelt in die legitimering van kennis een grote rol (Apple, 2013). En afgaande op bovenstaande zelfpresentatie lijkt de heersende kennisopvatting in het bestuurskundig onderwijs vooral gericht op instrumentele kennis, namelijk probleemoplossende kennis. Dit contrasteert met een meer kritische kennisopvatting waarbij kennis juist onzekerheid toevoegt. De Amerikaanse schrijver Robert Westbrook omschreef dit als 'a way of knowing in a world without certainty' (Schinkel, 2013, p. 27). Kennis draait dan niet zozeer om het reduceren van complexiteit, maar om het toevoegen van complexiteit. Nieuwe kennis voegt namelijk altijd nieuwe vragen toe. Kennis is daarmee niet de afsluiting van, maar veelal de opening voor nieuwe kennisvragen. Met andere woorden: meer kennis betekent veelal meer onzekerheid (Schinkel, 2013).

Zeker waar het gaat om een academische opleiding bestuurskunde, zou kennis niet altijd ten dienste hoeven staan van het 'oplossen van maatschappelijke problemen'. Zo beargumenteert de Amerikaanse socioloog Michael Burawoy (2004; 2005) dat er verschillende typen kennis worden geproduceerd voor verschillende publieken.

Doorvertaald naar bestuurskunde zou een professionele bestuurskunde zich richten op instrumentele kennis voor bestuurskundigen, zoals gedegen methodenonderzoek. De beleidsbestuurskunde houdt zich dan bezig met het vormen van adviezen voor overheidsorganisaties. Kritische bestuurskunde doet bijvoorbeeld onderzoek naar de theoretische grondslagen van het vakgebied, terwijl een publieke bestuurskunde zich weet te engageren met maatschappelijke partijen om bijvoorbeeld tot nieuwe vormen van kennis te komen.

Dit ideaaltypische onderscheid toont de meervoudigheid van kennis. En als we dit toepassen op de bestuurskundige zelfpresentatie, dan ontvouwt zich een nogal eenzijdige nadruk op instrumentele kennis. Deze nadruk op toepassing en kennisintegratie ('word probleemoplosser!') zorgt ervoor dat opleidingen zich vooral presenteren als professionele of beleidsbestuurskunde. Dat is zonde. Want ondanks dat deze dominantie van die beleidsbestuurskundige variant historisch te verklaren is (Rutgers, 2004; Van Ostaijen, 2016), levert het een tamelijk eng en arm beeld op van bestuurskundig onderwijs en blijft daarmee veel potentie onbenut. 


\section{Kritiek in bestuurskundig onderwijs}

Die professionele of beleidsbestuurskundige nadruk heeft consequenties voor de bestuurskundige onderwijsopvatting. Ondanks deze meervoudigheid van kennisvormen zien we een tamelijk enge invulling van bestuurskundeopleidingen, als we afgaan op de externe presentatie. En dat is problematisch, zeker voor een academische variant van bestuurskundig onderwijs. Wat ons betreft, dient academisch onderwijs juist die meervoudigheid en variëteit aan typen kennis volwaardig te adresseren binnen haar curricula. Een enge focus op zoiets als beleidsbestuurskunde heeft als risico dat studenten op voorhand eenzijdig worden benaderd als probleemoplossende beleidsprofessionals, strategen, ingenieurs en adviseurs. Die enge benadering laat veel potentie onbenut, want 'we zijn er tenslotte niet om bestuurders te behagen' (Van Twist, 2010, p. 24). Bovendien maakt dat bestuurskundeopleidingen onnodig instrumenteel. Daarom is kritisch bestuurskundig onderwijs van belang.

\section{Kritische methode}

Met 'kritische' bestuurskunde doelen we niet op 'kritiek' als per definitie normatieve of objectieve kritiek in de marxistische traditie. Met 'kritische bestuurskunde' sluiten we qua type kennis aan bij onder meer het werk van Burawoy (reflexieve kennis voor academische publieken), en qua methode (problematisering en deconstructie) aan bij Alvesson en Sandberg (2011) en Bacchi (2012).

Allereerst een voorbehoud, want 'kritisch zijn' lijkt nogal en vogue. Lekker 'brainstormen', 'out-of-the-box' redeneren en 'disruptive' denken zijn inmiddels geijkte bedrijfskundige communicatievormen. Dat betekent dat kritiek in een kapitalistisch systeem eenvoudig geïnstrumentaliseerd kan worden om de bestaande orde verder te legitimeren. Het is ons niet om deze salonfähige variant van kritiek te doen. Met kritische methode doelen we eerder op een 'problematiseringsmethode' waarmee onderzocht kan worden hoe probleemdefinities en sturingspraktijken ontstaan en gelegitimeerd worden (Jhagroe, 2016; Van Ostaijen, 2017). Dat kan door het bevragen van genormaliseerde kennis als 'feiten' en door concepten en praktijken te benaderen zonder een a priori maar een immanent beoordelingskader. Het is bijvoorbeeld inspirerend om studenten niet een antwoord op een al bestaand beleidsprobleem te laten formuleren, maar studenten de mogelijkheid te geven om een gangbare problematisering te bevragen. Daarmee wordt het mogelijk om je af te vragen waarom een maatschappelijk issue ooit een beleidsprobleem is geworden. Dit creëert ruimte om op een alternatieve (en minder geïnstrumentaliseerde) manier met kennis om te gaan. Die kritische positie maakt het mogelijk om de maatschappelijke orde te confronteren met de spanning tussen dat wat is ('het actuele') en dat wat kan zijn ('het potentiele') (Schinkel, 2013; Glynos \& Howarth, 2007). Een dergelijke methode vertrekt vanuit de assumptie dat elke maatschappelijke orde: (1) tijdelijk is en contingent; (2) alternatieven uitsluit; (3) bestaande ongelijkheden reproduceert. 
Er is een rijk arsenaal aan inspirerende denkers (zoals Nietzsche, Adorno, Foucault en Deleuze, maar ook Swyngedouw, Laclau en Dikeç) die docenten én studenten kunnen leren om tot een denaturalisering van machtspraktijken te komen. Daarmee wordt het mogelijk om de common sense te bevragen, binnen politieke, beleidsmatige of wetenschappelijke kennisdomeinen, zoals wij in dit artikel op een beknopte wijze doen voor bestuurskundeopleidingen. Deze kritische methode behelst daarbij het inbrengen van wat aanvankelijk niet zichtbaar, zegbaar en denkbaar is. Het is een manier om alternatieve, of historisch gezien uitgesloten, perspectieven te laten interveniëren (Howarth \& Griggs, 2012). Dat geeft ruimte aan studenten om vanuit een reflexieve positie bestaande normen en hegemonische begrippen te abnormaliseren. Het problematiseert de rol van macht zonder een claim op objectieve feiten te doen, maar juist het partiële karakter van objectiviteit te onderzoeken.

\section{Een pleidooi voor kritisch bestuurskundig onderwijs}

Deze kritische methode en kritische kennis zijn júist noodzakelijk binnen bestuurskundig onderwijs omdat bestuurskunde zich richt op macht, orde en ordening zoals in beleid, wet- en regelgeving. Hoewel het klassieke governmentdenken inmiddels passé lijkt, is de focus op governance-arrangementen, netwerken en co-creatie weinig anders dan oud maakbaarheidsdenken in nieuwe vaten (Van Putten, 2015). In die zin is 'ambachtelijk netwerkmanagement' geen beperking van het planningsdenken, maar een hernieuwde poging tot de vervolmaking ervan. Of denk aan hoe netwerkoptimisme en governance-modellen 'horizontaal' lijken, maar uiteindelijk ook bepaalde groepen uitsluiten, of aan hoe nudging vooral gedrag problematiseert bij groepen met een veelal lage sociaaleconomische status (Howarth, 2010). Met andere woorden, júist in een tijd waarin 'nudging', 'co-creatie' en 'netwerkvorming' domineren, is een kritische positie noodzakelijk. Daarom is het van belang dat vooral bestuurskundestudenten zich reflexief positioneren tot orde en ordening. Het zijn met name deze studenten die baat hebben bij kritisch bestuurskundige kennis én methoden.

\section{Productieve subversiviteit}

Kritisch bestuurskundig onderwijs hoeft niet opnieuw te worden uitgevonden. Er zijn talloze auteurs en bronnen die kunnen inspireren om die kritische pedagogie vorm te geven (Freire, 1973; Bacchi, 2012; Darder, 2003; Glynos \& Howarth, 2007; Bevir, 2013). Deze benaderingen leggen niet alleen de nadruk op kritiek in relatie tot politiek-bestuurlijke praktijken, maar ook op de democratisch-emancipatoire betekenis van kritiekbeoefening. Daarmee kun je toewerken naar een vorm van productieve subversiviteit.

Allereerst spoort het studenten en docenten aan om bijvoorbeeld samen dominante discoursen en praktijken te problematiseren en op basis daarvan alternatieven te ontwikkelen. Het stelt studenten in staat om hun eigen epistemische positie te bevragen middels de problematisering van een beleidsprobleem. Dat kan 
beginnen bij het stellen van de juiste vraag. Waarom spreekt men over een 'migratiecrisis' en wie mag dat doen? Welke groepen worden structureel uitgesloten in het debat over het 'klimaatprobleem'? Welke reproductie van ongelijkheid zit besloten in het armoedebeleid? Voor welk probleem kan werkloosheid de oplossing vormen? Zijn algoritmen seksistisch? Hoe komt het dat de loonkloof veelal wordt geproblematiseerd door mannen bij vrouwen? En waarom zien we expats niet als migranten? De juiste vraag kan aanzetten tot alternatieve kennis en maakt een ander type 'praktijkrelevantie' mogelijk. Daarbij gaat het niet zozeer om het 'ontmaskeren' van bestaande kennis en machtspraktijken, maar om alternatieve vormen van verbeelding mogelijk te maken (Wright Mills, 2000). Ten tweede, een kritische pedagogiek is niet geheel vrijblijvend en vergt intensieve zelfreflectie en zelfonderzoek. Dit resoneert met de onderwijstraditie in bijvoorbeeld Liberal Arts, waarbij studenten primair worden benaderd als burgers (niet als ingenieurs of beleidsmatige probleemoplossers) en worden gezien als cruciaal onderdeel van een democratische samenleving. Zo pleit Martha Nussbaum (2010) voor geesteswetenschappelijk en verkennend leren, waarbij het van belang is om vragend na te denken. Deze vorm van onderwijs biedt mogelijkheden om aan te haken op het engagement van studenten om inhoud gestalte te geven en discussies te entameren. Het betekent vanuit een andere startpositie samen lezen, onderzoek doen en schrijven. Dit kan tot uiting komen in nieuwe leerdoelen, werkvormen, scriptieonderwerpen, begeleidingskeuzes, toetsingstypen en vormen van normering.

\section{Conclusie}

Bovenstaande exercitie toont niet alleen wat kritische kennis en methoden zijn, maar tevens hoe deze kunnen worden toegepast en wat dat oplevert. Door de huidige bestuurskundige zelfpresentatie en de daarbij geëtaleerde instrumentele kennisopvatting te problematiseren bevragen we die norm en verbeelden we een alternatief onderwijsperspectief. Daarmee is bovenstaande analyse niet alleen een inhoudelijke bijdrage om bestuurskundige kennis te herbronnen met alternatieve denkers. Het is tevens een reflexieve didactische en pedagogische bijdrage om bestuurskundig onderwijs letterlijk te her-vormen, middels alternatieve methoden. Daarmee bieden we een ander perspectief op het type kennis en methoden om maatschappelijke en bestuurskundige vraagstukken te analyseren. Namelijk vanuit kritische kennis en methoden.

Laat dit een aanzet zijn om te werken met inspirerende onderwijsvormen die vertrekken vanuit de door ons verbeelde productieve subversiviteit. Het is niet alleen noodzakelijk voor het bestuurskundig vakgebied, onze toekomstige studenten verdienen het ook. 


\section{Literatuur}

Alvesson, M., \& Sandberg, J. (2011). Generating research questions through problematization. Academy of Management Review, 36(2), 247-271.

Apple, M. (2013). Can education change society? New York, NY: Routledge.

Braun, C., Fenger, M., Hart, P. T., van der Veer, J., Verheij, T., \& van der Wal, Z. (2015). Quo vadis, Nederlandse Bestuurskunde?. Bestuurskunde, 24 (4), 82-92.

Bacchi, C. (2012). Why study problematizations? Making politics visible. Open Journal of Political Science, 2(1), 1-11.

Bevir, M. (2013). A theory of governance. Berkeley: University of California Press.

Braam, A. van. (1989). Filosofie van de bestuurswetenschappen. Leiden: Martinus Nijhoff.

Burawoy, M. (2004). Public sociologies: Contradictions, dilemmas, and possibilities. Social Forces, 82(4), 1603-1618.

Burawoy, M. (2005). 2004 American Sociological Association presidential address: for public sociology. The British journal of sociology, 56(2), 259-294.

Darder, A. (2003). The critical pedagogy reader. Hove: Psychology Press.

Freire, P. (1973). Education for critical consciousness. London: Bloomsbury Publishing.

Glynos, J., \& Howarth, D. (2007). Logics of critical explanation in social and political theory. London: Routledge.

Heinich, N. (2019). Wat onze identiteit niet is. Amsterdam: Prometheus.

Howarth, D. (2010). Power, discourse, and policy: Articulating a hegemony approach to critical policy studies. Critical Policy Studies, 3(3-4), 309-335.

Howarth, D. and Griggs, S. (2012) Poststructuralist policy analysis : discourse hegemony and critical explanation. In: Fischer, F. and Gottweiss, H. (eds.) The argumentative turn revisited : public policy as communicative practice. Durham, North Carolina : Duke University Press.pp. 305-342

Jhagroe, S.S. (2016). Urban transition politics: How struggles for sustainability are (re)making urban spaces. Rotterdam: DRIFT.

Jong, P. de. (1988). Bruggen bouwen. Amsterdam: Siswo.

Nussbaum, M.C. (2010). Not for profit: Why democracy needs the humanities (Vol. 2). Princeton, NJ: Princeton University Press.

Ostaijen, M. van. (2016). De wil van Wilson: Onder bestuurskundigen - een reflectie op de zelfreflectie en een pleidooi voor bestuurskunde als politieke wetenschap. Bestuurskunde, 25(4), 94-104.

Ostaijen, M. van. (2017). Word between worlds: The politics of intra-European movement. Ridderkerk: Ridderprint.

Poppelaars, C.H.J.M., Hart, P. 't, Fenger, M., Veer, J. van der, \& Verhey, T. (2015). Quo vadis, Nederlandse Bestuurskunde? Bestuurskunde, 24(4), 82-92.

Putten, R.J. van. (2015). Bestuurskunde voorbij het maakbaarheidsdenken? Bestuurskunde, 24(2), 74-84.

Rutgers, M. (1993). Tussen fragmentatie en integratie. Delft: Eburon.

Rutgers, M. (2004). Grondslagen van de bestuurskunde. Bussum: Coutinho.

Schinkel, W. (2013). De publieke taak van de universiteit. Science in Transition. Verkregen van https://scienceintransition.nl/app/uploads/2013/09/

SCHINKEL_DePubliekeTaakVdUniversiteit-2013-0622.pdf

Twist M.J.W. van (2010). Over (on)macht en (on)behagen in de beleidsadvisering. Den Haag: Boom/Lemma

Wright Mills, C. (2000). Sociological imagination. Oxford: Oxford University Press. 